\title{
A sala de aula como espaço de partilha: análise sob a ótica da complexidade de experiências em uma disciplina de mestrado
}

\author{
Stephany Sousa \\ Universidade Estadual de Goiás \\ stephanymsousa@gmail.com \\ https://orcid.org/0000-0002-5593-0833 \\ Vinícius Fagundes \\ Universidade Estadual de Goiás \\ viniciusfagundes_@hotmail.com \\ https://orcid.org/0000-0001-9925-7823 \\ João Henrique Suanno \\ Universidade Estadual de Goiás \\ joao.suanno@ueg.br \\ https://orcid.org/0000-0003-0624-5378
}

RESUMO: O artigo pretende analisar, sob a ótica da complexidade, experiências compartilhadas pelos mestrandos numa disciplina de Educação e Diversidades, ministrada em 2020, em contexto pandêmico da COVID-19. O objetivo central é destacar nos comentários formulados pelos discentes em roteiros propostos pelas docentes, sob uma ótica complexa, como a metodologia proposta contribuiu para a criação de um espaço de partilha dos relatos na temática da diversidade. A pesquisa é bibliográfica, de abordagem qualitativa, sendo utilizados os operadores cognitivos do pensamento complexo, de Edgar Morin, como categorias de análise. Como aporte teórico, fundamenta-se em Candau (2000); Freire (1996); Hooks (2013); Maturana (2002); Morin (2007); Nicolescu (1999); Valente (2008); e Suanno (2013). Concluiu-se que a sala de aula é ambiente de trocas e partilhas, para além de estruturas físicas, ambiente propício para construção de saberes e formação de sujeitos complexos, para além dos conteúdos disciplinares e programáticos. Foram encontradas possibilidades de pensar pelos operadores cognitivos do pensamento complexo.

PALAVRAS-CHAVE: Educação. Complexidade. Diversidade. Sala de Aula. Partilha.

\section{CLASSROOM AS A SHARING SPACE: ANALYSIS FROM THE PERSPECTIVE OF THE COMPLEXITY OF EXPERIENCES IN A SUBJECT OF A MASTER COURSE}

ABSTRACT: The article intends to analyze, from the perspective of complexity, experiences shared by master's students during an Education and Diversity course taught in the second half of 2020, in a pandemic context. The main objective is to highlight in the comments made by the students in scripts proposed by the teachers, under a complex perspective, how the proposed methodology contributed to the creation of a space for sharing experience reports on the theme of diversity. Bibliographic research, with a qualitative approach. Using the cognitive operators of complex thinking, by Edgar Morin. As a theoretical contribution, it is based on Candau (2000), Freire (1996), Hooks (2013), Maturana (2002), Morin (2007), Nicolescu (1999); Brave (2008). It was concluded that the classroom is an environment for exchanges and sharing, in addition to physical structures, a favorable environment for the construction of knowledge and training of complex subjects, in addition to disciplinary and programmatic contents. Possibilities of thinking were found by the cognitive operators of complex thinking.

KEYWORDS: Education. Complexity. Diversities. Classroom.Sharing. 


\section{INTRODUÇÃO}

Pandemia do Corona Vírus, lockdown, COVID-19, isolamento, distanciamento social, máscaras. O mundo parou, mas a falta de relacionamento humano não. A educação não. Somos a resistência. A sala de aula que nunca se resumiu ao espaço físico se transformou e as formas de interação também. Professores e alunos se reinventaram. Nós, alunos, durante o segundo semestre de 2020 do Programa Pós-Graduação Stricto Sensu Interdisciplinar em Educação, Linguagem e Tecnologias (doravante denominado pela sigla PPG-IELT), sediado na Universidade Estadual de Goiás, na Unidade Universitária de Ciências Socioeconômicas e Humanas - UnUCSEH, Anápolis, Goiás, vivenciamos com outros discentes do programa do mestrado PPG-IELT a experiência de partilhar relatos de vida na disciplina de Educação e Diversidades, ministrada pelas professoras Marlene Barbosa de Freitas Reis e Viviane Pires Viana Silvestre.

Após observar as ações das professoras ao proporem a construção colaborativa do plano de ensino, com a junção de aulas e atividades síncronas e assíncronas, a elaboração do artigo final da disciplina não poderia ter outra temática senão a sala de aula. A nós, autores, coube a tarefa de selecionar, para a construção do presente artigo, dentre os roteiros de estudos produzidos ao longo do semestre, aqueles que continham histórias de vivências dos mestrandos em suas atuações profissionais. Para tanto, eles serão aqui nomeados por heterônimos fictos (João, Pablo, Roberta, Maria, Divina e Joana) ${ }^{1}$.

Ulteriormente à seleção dos relatos partilhados livremente pelos alunos na última parte dos roteiros e a escolha do referencial bibliográfico que fundamentou a base teórica da presente pesquisa, foram observadas as ações docentes que contribuíram para a formação dessa sala de aula como a própria vida pulsante em uma perspectiva complexa, que se fundamenta em Edgar Morin.

A justificativa para o presente estudo se baseou na inquietação surgida pela suspensão das aulas presenciais, o que despertou nosso olhar para analisar a atuação dos professores nas atividades síncronas e assíncronas, utilizando de meios virtuais para formarem suas salas de aula como espaços autênticos da produção de saberes.

Ao vivenciarmos a disciplina de Educação e Diversidades do referido programa de pós-graduação stricto sensu e conhecer a proposta de elaboração de um plano de ensino de forma conjunta e gradual, percebemos que a sala de aula ali construída era fonte e poderia ser o objeto de estudo do artigo final da disciplina. Assim, a construção do plano de ensino com a participação de todos os envolvidos no processo de ensino-aprendizagem, alunos e professores, contou com todo o suporte de organização das docentes, que apresentaram modelos de roteiros e templates, divisão de temáticas, sugestões de bibliografias e outros suportes.

Já a construção do quadro teórico se deu ao longo da disciplina e alguns autores se destacaram no levantamento bibliográfico, pois traziam a temática da sala de aula associada à afetividade e ao respeito à diversidade. Outros autores foram agregados após a

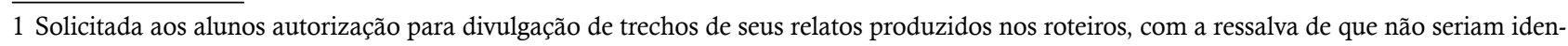
tificados, mas adotados nomes fictos para as referências. 
pesquisa booleana em bancos de dados de dissertações, como a plataforma Scielo, para levantamento da relevância temática e de artigos já publicados na área.

Por sua vez, a metodologia utilizada se baseou em referenciais teóricos do tema, fazendo um diálogo entre a teoria e a prática, analisando as estratégias aplicadas em uma disciplina do mestrado em Goiás, por meio de observação, reflexão e análise das atividades e levantamento de narrativas em roteiros confeccionados pelos alunos.

A estrutura do trabalho foi dividida em seções, a contar da introdução, com a apresentação da metodologia utilizada, detalhando a construção do modelo teórico e do perfil metodológico. Na sequência, uma breve descrição da disciplina e dos instrumentos de aprendizagem empregados (roteiros, convidados, rodas de conversa, seminários da disciplina). No próximo subtítulo, elencamos os resultados e discussões da análise dos roteiros dos discentes e da religação de saberes para a construção da sala de aula como local de partilha. Por fim, as conclusões desta investigação, mesmo que provisórias, seguidas das referências bibliográficas.

A pesquisa realizada apoia-se na pesquisa documental, uma vez que foi escolhido como alternativa utilizar materiais já existentes que são os roteiros de estudos desenvolvidos pelos discentes na disciplina em estudo. Tais roteiros foram considerados documentação, visto que servirão de fundamento para que as professoras realizem a correção, análise e, consequentemente, pontuem este trabalho, atribuindo aos discentes os créditos necessários e correlatos. Segundo Flick (2013, p.124) "a análise dos documentos pode se referir a materiais existentes - como diários - que não foram ainda usados como dados em outros contextos". Esse foi o caso desta pesquisa, já que os roteiros utilizados para esta análise compuseram-se de elemento avaliativo por parte dos docentes da disciplina do programa de mestrado já supracitado.

O foco de análise do artigo se deu justamente na última parte dos roteiros, sendo selecionados aqueles que continham os relatos da atuação docente, livremente partilhados pelos discentes do Programa.

\section{BREVE DESCRIÇÃO DA DISCIPLINA E DOS INSTRUMENTOS DE APRENDIZAGEM EMPREGADOS}

A disciplina de Educação e Diversidades ministrada no Programa de Pós-Graduação Stricto Sensu Interdisciplinar em Educação Linguagens e Tecnologias (PPG-IELT), da Universidade Estadual de Goiás - UEG, durante o segundo semestre de 2020, contou com o desafio de se adaptar ao contexto de pandemia, vivenciado pela humanidade, por conta da Covid-19, com todas as exigências e protocolos de segurança para evitar a contaminação pelo Corona Vírus. Assim, suspensas as aulas presenciais na unidade de ensino, foram realizadas aulas síncronas via plataforma Google Meet, e atividades assíncronas para o desenvolvimento das tarefas pedagógicas.

Desde o primeiro encontro, foi disponibilizado pelas professoras um link fixo de acesso às aulas, bem como apresentada a proposta para confeç̧ão de roteiros, com um modelo de estrutura a ser seguido, o qual era enviado por e-mail pelos alunos até o meio dia, antes do encontro. Os roteiros eram ferramentas que incentivavam as leituras prévias 
sugeridas, além de reforçarem a construção de textos seguindo as normas da ABNT, pois eram retiradas das leituras citações e trechos de destaque nas obras estudadas para debate em aula, nos formatos de rodas de conversa, conduzidos por grupos de dois ou três alunos, que direcionavam a introdução do tema e sugeriam bibliografias lidas previamente e discutidas em sala de aula virtual.

A disciplina contou com 21 (vinte e um) acadêmicos, entre alunos regulares do programa e alunos especiais, e ao seu término foram disponibilizados por eles, no drive da disciplina, um roteiro para cada encontro. Dos 08 (oito) encontros realizados, com proposta de roteirização, totalizaram 168 roteiros. Desses, foram triados 19 (dezenove) inicialmente, os quais continham relatos pessoais e, dentre eles, selecionados por nós autores 11 (onze) roteiros como fonte de análise para confecção do presente artigo. As aulas ocorreram de forma virtual, através de nossas conexões pela internet e por vezes seguiam o formato de seminário no primeiro momento e roda de conversa na segunda parte, em sua maioria com a participação de convidados (entre eles autores de textos estudados), o que também contribuía para a participação dos alunos de forma entusiasmada e colaborativa.

Antes de cada encontro, os alunos que conduziriam a roda de conversa eram orientados de forma particular pelas professoras, que alinhavam as temáticas e a indicação de leituras, filmes, documentários, enfim, todo o material que seria fonte de preparação para o encontro semanal.

Na sequência, os encontros síncronos ocorriam no formato de seminários liderados por grupos diferentes de alunos em cada aula e, no segundo momento, a roda de conversa, com a discussão temática.

\section{A CONSTRUÇÃO DE UMA SALA DE AULA VIVA SOB UMA ANÁLISE COMPLEXA}

O que é uma sala de aula? Ao pensarmos no espaço físico de paredes, dimensionamos apenas o aspecto material dessa estrutura e reduzimos algo complexo à objetividade. $\mathrm{Na}$ verdade, durante a pesquisa restou evidente o conceito de sala de aula como algo além do espaço físico, como lugar de relações, de afeto, de trocas, de formação e de transformação, onde a experiência pedagógica - o ensinar e o aprender - é desenvolvida no vínculo: tem uma dimensão histórica, intersubjetiva e intra-subjetiva (VALDEZ, 2002, p. 24).

Pensar a sala de aula como um ambiente formativo e vivo pelas lentes da complexidade é também compreender a multidimensionalidade, as multifaces desse ambiente e também dos elementos fundantes que a constituem: alunos, professores, conhecimentos, métodos, didática em uma relação dialógica e não disjuntiva, mas complexa, isto é, relações que são tecidas como uma teia, como uma rede (MORIN, 2007).

Para nos auxiliar a ampliar os olhares sob essa perspectiva complexa, baseamo-nos em Moraes e Valente (2008), Suanno, M.V.R. (2015), Suanno, J.H. (2013) e demais autores que pensam a complexidade sob a ótica de Edgar Morin. Destarte, apresentamos os operadores cognitivos do pensamento complexo que servirão como balizadores dos 
apontamentos e dos olhares que fizemos sobre os relatos que aqui forem tecidos. São eles: a) princípio sistêmico-organizacional; b) princípio hologramático; c) princípio retroativo; d) princípio recursivo; e) princípio dialógico; f) princípio auto-eco-organizador ou autoprodução; g) princípio da reintrodução do sujeito cognoscente no processo de construção do conhecimento; h) princípio ecológico da ação; i) princípio da enação; e j) princípio ético (MORAES; VALENTE, 2008).

A dinâmica teórica aqui apresentada não é a de descrever em detalhes cada um desses operadores, mas ir apresentando-os de acordo com o desenvolver das análises dos discursos presentes nos relatos, a fim de correlacionar essas observações aos operadores do pensamento complexo e dialogar sobre eles nesta interconexão que propomos. Assim sendo, de acordo com a percepção que obtivermos no decorrer da elaboração conceitual do texto, correlacionaremos o(s) referido(s) operador(es) cognitivo(s) ao relato de experiência para poder ampliar o olhar sobre a referência e sobre as relações com tais operadores.

Partindo do modelo de educação ainda vivenciado, que prioriza conhecimento racional em detrimento da afetividade e da formação integral, se revela a importância do objeto de estudo, pois, diante das análises realizadas, percebemos que as estratégias de gestão de sala de aula adotadas pelas professoras da disciplina foram capazes de aliar conhecimento e emoções, transcendendo limites teóricos e avançando para o que Nicolescu (1999) trataria como temáticas transdisciplinares, uma vez que tais assuntos adentraram o que está entre as disciplinas, através das diversas disciplinas e para além de qualquer disciplina, com o intuito de compreender e modificar o mundo.

Maturana $(1999$, p.15) nos afirma que "vivemos uma cultura que desvaloriza as emoções, e não vemos o entrelaçamento cotidiano entre razão e emoção, que constitui o viver humano, e não nos damos conta de que todo sistema racional tem um fundamento emocional", sem muitas vezes nos atentar que o ser humano é dotado de multifaces e peculiaridades que the são inerentes, rodeados por relações humanas, sociais, culturais, filosóficas, cognitivas que contribuem para a formação do ser complexo, integrado, religado e multidimensional (MORIN, 2007).

Pensemos na sala de aula também como espaço transformado pelo tempo e pelo surgimento de inovações e descobertas no processo de ensino-aprendizagem. Assim como a própria escola mudou, mudaram as formas de interação nela. O que antes era regido por autoritarismo na relação aluno-professor deu espaço para cenários de vínculos, diálogos, exposições e afetividade.

Sob a perspectiva de Candau (2000, p.13), "a escola precisa ser espaço de formação de pessoas capazes de serem sujeitos de suas vidas, conscientes de suas opções, valores e projetos de referência e atores sociais comprometidos com um projeto de sociedade e humanidade". Isso posto, faz-se necessário que os alunos sejam autores de sua própria formação e atuação na sociedade de forma autônoma e efetiva. Sob esse aspecto apresen- 
tado por Candau (2000), retomamos o conceito de reintrodução do sujeito cognoscente, que se constitui como um dos operadores cognitivos do pensamento complexo.

Suanno (2013, p. 64) nos traz sua percepção sobre o conceito de reintrodução do sujeito cognoscente atestando que "a reinserção do sujeito cognoscente resgata a corporeidade a partir da relação cognitiva e afetiva, ao mesmo tempo em que o transforma em um sujeito que busca a construção de um mundo melhor". Assim sendo, essa ação reintegra o aluno de forma efetiva a fim de que ele seja autor de sua aprendizagem, criador do pensamento e construtor de seu próprio conhecimento, sendo também mediado pelo professor.

Se a escola se constrói em espaços de formação humana, a universidade também, a seu exemplo, não se limita a sala de aula física, mas transcende barreiras e pode se dar em muitos contextos, inclusive no ambiente virtual. Perspicaz então a estratégia das professoras de propor seminários liderados por grupos diferentes de alunos em cada encontro e, no segundo momento, a roda de conversa, com estímulo para que todos pudessem tirar suas dúvidas, fazer contribuições, propor reflexões e conexões das temáticas estudadas. Nesse sentido, Morais (1991, p. 45) nos atesta que "a via que está aberta é a da sala de aula como veiculação de um discurso que faça florescer a consciência crítica, não a idealista, mas a resultante das injunções histórico-sociais, aquela fundada nas relações concretas". Retomamos mais uma vez o operador da reinserção do sujeito cognoscente, que resgata a voz ativa de quem constrói seu próprio conhecimento, aliado ao apoio e mediação dos professores e dos demais partícipes da disciplina na construção dos saberes coletivos.

Em diversos encontros, eram destacados trechos de produção dos alunos nos roteiros, o que direcionava as discussões das rodas de conversa e nos diálogos entre os discentes. É oportuno salientar que tais direcionamentos feitos pelas professoras não se davam de forma autoritária. E mesmo a construção dos seminários não revelou falta de diretividade das professoras, pelo contrário. Como defende Freire (1996),

Qualquer que seja a qualidade da prática educativa, autoritária ou democrática, ela é sempre diretiva. No momento, porém, em que o educador ou a educadora interfere na capacidade criadora, formuladora, indagadora do educando, de forma restritiva, então a diretividade necessária se converte em manipulação, em autoritarismo (2000, p. 79).

O ensinar e o aprender não estão desvinculados de nossas leituras de mundo e da forma como nos vinculamos ao outro e nos conectamos com ele. Esse sentimento de pertencimento identitário pode ser visto nas construções dos relatos dos discentes que, após estudarem a bibliografia sugerida na temática do encontro, conseguiram relembrar ocasiões em que vivenciaram em suas práticas histórias que mereciam ser compartilhadas.

Conforme nos apontam Selma Pimenta e Léa Anastasiou (2010) sobre o ensino enquanto prática social, "O ensino, fenômeno complexo, enquanto prática social realizada por seres humanos com seres humanos, é modificado pela ação e relação desses sujeitos, que, por sua vez, são modificados nesse processo" (2010, p. 189). 
Assim, a criação de um ambiente de sala de aula onde todos se sentiram, de fato, colegas de profissão, independente de instâncias ou níveis de docência, foi primordial para a partilha das vivências nos roteiros.

Sobre tais práticas, salientamos a observação do princípio sistêmico-organizacional que, segundo Moraes e Valente (2008), é um princípio que nos ajuda a ligar o conhecimento das partes ao conhecimento do todo, salientando-nos sobre a impossibilidade de conhecer o todo sem se conhecer as partes e, nessa mesma lógica, retroagimos ao mesmo conceito de que é impossível conhecer as partes sem também conhecer o todo.

Como exemplo, a disciplina Educação e Diversidades contou com as histórias de vida, relatos e obras teóricas de convidados/as que abordaram as mais diversas frentes da diversidade e diferença, entre elas, abordagens sobre a interculturalidade, alteridade e educação, direitos humanos, diversidade e inclusão, identidade, alteridade e diferença, desigualdades, língua e escola, relações étnico-raciais, LGBTQIA+, educação indígena, educação quilombola e do campo, educação especial e necessidades especiais. Isso posto, podemos inferir que não há como conhecer sobre a temática da diversidade sem também conhecer as dimensões e especificidades abarcadas nessa temática, confirmando, assim, não somente o princípio sistêmico-organizacional, mas também o princípio hologramático que, segundo Morin (2007), nos aponta que o todo está intrinsecamente nas partes como as partes estão presentes no todo.

Esta análise nos mostrou que a temática da diversidade estava intrinsecamente ligada e interconectada a todas as partes correlatas da disciplina já supracitadas. Assim sendo, torna-se quase que impossível abordar um subtema sem também tocar no assunto da diversidade como um todo. Sob essa luz, apontamos tanto a presença do princípio hologramático quanto do princípio sistêmico-organizacional. A fim de elucidar o conceito acima elaborado, trazemos Suanno (2015), que nos atesta:

Pensar complexo por meio do princípio sistêmico-organizacional remete à necessária articulação ao princípio hologramático, uma vez que a parte possui sua singularidade e sua individualidade e o todo está também inscrito nas partes. Pensar por meio do princípio hologramático significa compreender que não somente a parte está no todo, mas o todo está também inscrito nas partes (Suanno, 2015, p. 99).

Por meio do mesmo método comparativo utilizado por Suanno (2015), correlacionamos o princípio hologramático como presente nas análises, uma vez que, como a disciplina tinha como intuito discutir e construir conceitos acerca das diversidades, faz-se necessário compreender essa diversidade em amplas dimensões, isto é, dimensões de gênero, sociais, étnicas, dentre outras. Para tanto, enxergar a diversidade é também enxergar as diferenças e não há como enxergar tais diferenças sem compreender que a diversidade está intrínseca a elas, tendo assim um caráter hologramático, onde as diferenças então no todo da diversidade e vice-versa.

Retornando aos conceitos da disciplina analisada, trazemos o exemplo do que defendeu Hooks (2013) sobre o comportamento do mestre em sala de aula. A autora afirma 
que "nunca quisera abandonar a convicção de que é possível dar aula sem reforçar os sistemas de dominação existentes. Precisava ter certeza de que os professores não têm de ser tiranos na sala de aula." (HOOKS, 2013, p. 25). Essa forma de educação que ensina para além dos conteúdos e incentiva o protagonismo do processo de aprendizagem pressupõe a atuação de professores que enxerguem os seres humanos em sua integralidade, em sua totalidade.

A educação como prática da liberdade é um jeito de ensinar que qualquer um pode aprender. Esse processo de aprendizado é mais fácil para aqueles professores que também creem que sua vocação tem um aspecto sagrado; que creem que nosso trabalho não é o de simplesmente partilhar informação, mas sim o de participar do crescimento intelectual e espiritual dos nossos alunos. Ensinar de um jeito que respeite e proteja as almas de nossos alunos é essencial para criar as condições necessárias para que o aprendizado possa começar do modo mais profundo e mais íntimo (HOOKS, 2013, p. 25).

Quando se fala na construção de uma sala de aula viva, como denominamos no artigo, se relembra justamente a educação como prática da liberdade, na medida em que não se reforça os modelos tradicionais de autoridade entre aluno(a) e professor(a), mas ao contrário, se estimula o protagonismo pensante, numa relação de profundo respeito, em um caminhar onde o ensinar e o aprender não se desvencilham.

Nesse sentido, Elias (1996) traz a teoria de Freinet, sustentando uma pedagogia natural na atuação dos professores.

[...] Freinet propõe uma pedagogia natural, "nova e popular" que enseja ao aluno não apenas o acesso à informação, mas também a apropriação do saber; uma pedagogia que, avessa ao imobilismo e a abstração, insere a alegria e o prazer no processo ensino-aprendizagem. Essa pedagogia - também entendida como Pedagogia do Bom Senso e Pedagogia do Sucesso - alicerçada, principalmente, nos seguintes princípios: Confiança e respeito ao ser humano e seus direitos. (ELIAS, 1996, p. 12).

É preciso também refletir sobre a via de mão dupla que é o processo de ensino-aprendizagem estabelecido em uma sala de aula, pois, durante o processo de mediar o conhecimento, o professor também aprende, se transforma e sofre influências em sua mediação, que pode ser de fato prazerosa, amigável e fundada no respeito mútuo.

O professor aprende enquanto ensina e se engrandece e se fortalece em seus atributos intelectuais tornando-se mais poderoso à medida que enriquece a sua personalidade. No entanto, o mais importante para o tema do ensino é precisamente sua capacidade de influir no comportamento de outros. E esse poder é de uma importância tão fundamental em termos sociais que o educador não apenas modifica o comportamento do educando ou do aluno, mas constitui a própria mediação, ou melhor, a construção de sua personalidade. (PARO, 2010, p. 50-51).

Essa influência não só decorre do tempo de atuação, mas do contato com a importância da afetividade em sala de aula. Como afirma Freire: 


\begin{abstract}
$\mathrm{Na}$ verdade, preciso descartar como falsa a separação radical entre seriedade docente e afetividade. Não é certo, sobretudo do ponto de vista democrático, que serei tão melhor professor quanto mais severo, frio, mais distante e "cinzento" me ponha nas minhas relações com os alunos, no trato dos objetos cognoscíveis que devo ensinar. A afetividade não se acha excluída da cognoscibilidade. O que não posso obviamente permitir é que minha afetividade interfira no cumprimento ético de meu dever de professor no exercício de minha autoridade... (1996, p. 159-160)
\end{abstract}

Na mesma medida em que o respeito ao ser humano integral e complexo, a afetividade se torna um importante elemento para o exercício do ofício de ensinar, não havendo relação entre frieza e ética. Pelo contrário, a afetividade faz parte da prática docente e, desde que não interfira no cumprimento do dever ético, será uma aliada do professor no desenvolvimento do processo de ensino-aprendizagem.

Ainda tratando do rico e complexo processo do que é ser professor e como sua atuação não se limita a muros ou paredes, afirma Teixeira (1996):

Sujeitos socioculturais são também seres concretos e plurais. São pessoas vivas e reais, existindo a partir de sua corporeidade e lugar social, a partir de sua condição de mulheres, homens, negros, brancos. Pertencem a diferentes raças e etnias. São crianças, jovens ou de mais idade; adeptos de variadas crenças e costumes. Têm desejos, projetos e atribuem variadas significações às suas experiências e ao mundo. Para entendê-los, é necessário considerar esses seus atributos, sejam eles adscritos ou adquiridos, pois tudo isso matiza sua existência e condição (TEIXEIRA, 1996, p. 185).

Assim, alunos e professores, como seres humanos complexos, únicos, são carregados de suas singularidades, histórias, desejos, planos, e, cada qual a seu modo, significam e ressignificam seus saberes, produzindo fontes diversas de conhecimentos, o que exige, para a compreensão dessa complexidade, a consideração de suas bagagens, também únicas.

\title{
PROCEDIMENTO METODOLÓGICO
}

Após finalizada a disciplina, foram levantados os roteiros disponibilizados pelos alunos em um Drive (ferramenta proposta pelas professoras), em formato PDF, e, após autorização deles, escolhidos os que continham partilhas de relatos vivenciados em suas práticas profissionais.

Assim, foram priorizados dentre a triagem 11 (onze) roteiros de estudo, confeccionados por 06 (seis) discentes do Programa, que converteram-se em fonte de análise do presente artigo, de forma a reforçar como as escolhas pedagógicas foram propícias para o formato de sala de aula favorável ao compartilhamento de emoções, vivências e histórias, tão essencial para o dinamismo do aprendizado que excede os conteúdos materiais, mas trabalha em prol da aprendizagem em sua totalidade. Isso se deu porque os alunos, ao receberem espaços de fala dados pelas professoras e ao serem estimulados por elas a escrever os roteiros e depois relatar suas histórias nas rodas de conversa, demonstraram 
que as escolhas pedagógicas das docentes foram capazes de encurtar distâncias físicas, criando uma sala de aula afetiva e acolhedora.

Para o desenvolvimento desse trabalho, não analisamos todos os conceitos de sala de aula ou fizemos a análise quantitativa dos roteiros, mas priorizamos a transcrição dos trechos de relatos de vivências dos estudantes, em uma abordagem qualitativa para reforçar a discussão de que a sala de aula como espaço de partilha é fundamental para a relação de ensino aprendizagem e para a autorreflexão pedagógica, especialmente sob o ponto de vista do canal de comunicação que resulte em respeito às diversidades e às diferenças, que permita a empatia e a conexão, unindo o científico e o afetivo, o objetivo e o subjetivo, sendo a autorreflexão o processo de repensar as próprias práticas docentes, na medida em que os alunos do mestrado são, em sua maioria, professores.

Pensando nesse lugar, onde teoria e prática se complementam como preparação para cada encontro, os discentes eram incentivados a grifar trechos, selecionar citações, elaborar comentários e críticas sobre as temáticas.

Educar é ensinar a olhar para fora e para dentro, superando o divórcio, típico da nossa sociedade, entre objetividade e subjetividade. É aprender além: saber que é tão verdade que a menor distância entre dois pontos é uma linha reta quanto que o que reduz a distância entre dois seres humanos é o riso e a lágrima (ALENCAR, 2001, p. 100).

Na sequência, os roteiros eram partilhados em aula, sendo fonte de análise pela turma que os relacionava com as experiências profissionais e com as temáticas propostas. Tal método permitia alinhar o conteúdo temático com as vivências partilhadas pelos alunos, construindo roteiros dinâmicos, contemplando a roteirização prévia e complementação dos saberes nas falas de todos (alunos, docentes e participantes convidados).

\section{RESULTADOS E DISCUSSÕES DA ANÁLISE DAS PARTILHAS DOS DISCENTES}

No roteiro de estudo de $\mathrm{n}^{\mathrm{o}}$. 04 , sobre a temática da desigualdade e a educação como prática de liberdade ${ }^{2}$, a aluna Maria demonstrou ter sua prática pedagógica afetada, após a leitura dos textos, passando a enxergar importância em atividades de incentivo à cultura, que antes eram tidas por ela como demasiadamente trabalhosas e pouco produtivas. Aluna Maria:

\footnotetext{
Depois da leitura que fiz do texto do Bourdieu passarei a defender os passeios aos eventos culturais como por exemplo visitação aos museus, teatros, exposições e eventos artísticos, pois não sabia desse quantitativo mínimo das visitas de crianças e jovens abaixo de quinze anos, e eu sempre fui contra por ser tão trabalhoso sair com as crianças das instituições escolares para essas atividades extracurriculares, hoje percebo que esse trabalho faz para da minha profissão e devo enfrentá-lo para ter um benefício maior que seria aumentar as chances relativas ao acesso à cultura das camadas populares.
}

2 BOURDIEU, Pierre. A escola conservadora: as desigualdades frente à escola e à cultura. In: NOGUEIRA, Maria Alice; CATANI, Afrânio (orgs). Escritos de Educação. Petrópolis: Editora Vozes, 2003. p. 39-64. HOOKS, Bell. Ensinando a transgredir: A educação com prática da liberdade. São Paulo: Ed. WNF Martins Fontes, 2013. p. 9-51 e 224-251. 
Foi fundamental o contato da aluna com os textos propostos para a compreensão da importância da escola como espaço de incentivo e acesso à cultura, já que muitos não possuem outra porta se não o ambiente escolar para ter contato com o teatro, parques, exposições de pinturas e outras formas de manifestação da cultura e da arte.

Na mesma temática, a aluna Roberta detalha sua atitude enquanto professora jovem e inexperiente, descrevendo como encarava o papel do professor e seu exercício de autoridade em sala de aula. Aluna Roberta:

No início da minha prática, por ser muito nova e temer a falha e/ou a críticas eu tentava ser mais autoritária possível, não permitia conversas e os/as alunos/as falavam somente quando eu pedia a participação, o silêncio me proporcionava um sentimento de autocontrole da sala e do contexto, mas, a falta de diálogo, de participação e de trocas, promovia aulas monótonas e cansativas. Ainda bem que atualmente tenho outras concepções. Todavia, infelizmente muitos/as educadores/as ainda pensam de maneira equivocada.

O aluno João partilhou sua vivência de professor em tempos pandêmicos da Covid-19, abordando como é relevante o acompanhamento de algum familiar na execução das atividades remotas. Aluno João:

A pandemia tornou algo mais evidente do que já se mostrava. Tenho observado o desenvolvimento dos meus alunos nas atividades não-presenciais. Geralmente, os que têm sempre algum familiar por perto, no momento de desenvolverem as atividades, conseguem acompanhar os conteúdos apresentados, entregam no horário estabelecido etc. Por outro lado, outros alunos não conseguem estabelecer horário para realizar as atividades ou têm muita dificuldade. Quando solicito a atividade, quase sempre, percebo que os responsáveis também não conseguem ajudar, ou mesmo que os alunos não tiveram ajuda de nenhum familiar.

Em tempos de pandemia da Covid-19 a fala do aluno partilhada no roteiro ganha ressonância com a situação enfrentada pelos estudantes pelo mundo todo. O distanciamento social como medida de prevenção ao Corona Vírus exigiu a participação da família para o desenvolvimento das atividades, levando a relação de ensino-aprendizagem também para os lares e evidenciando a importância da participação e do apoio familiar.

A participação efetiva da comunidade nos contextos escolares, não como expectadora do processo educativo, mas como protagonista, é essencial para uma formação democrática, coletiva e humanitária.

No roteiro abordando a temática de inclusão e construção étnico-identitária voltada aos indígenas ${ }^{3}$, a aluna Maria relata uma situação enfrentada por ela como professora em contato com a etnia Guajajara e como foi seu processo de incentivo ao diálogo e o respeito para inclusão dos alunos indígenas. Aluna Maria:

$\mathrm{Na}$ instituição em que eu trabalho, tem sete irmãos indígenas da mesma etnia. O nível de aprendizado deles é bem precário, eles preferem faltar às aulas para tomar banho em

3 KRENAK, A. O amanhã não está à venda. Companhia das Letras. São Paulo, SP: Editora Schwarcz S.A. 2020. SANTOS, P.; SILVA, E. D. Além do arco e flecha: a construção étnico-identitária a partir da educação bilíngue indígena Potiguara - PB. Revista Espaço Acadêmico, n. 199. p. 49-58, dez./2017. GUERRA, V. M. L. Entre a luta pela terra e o discurso da "inclusão", o processo identitário do indígena. In: PINTO, Joana P.; FABRÍCIO, Branca F. Exclusão social e microrresistências: a centralidade das práticas discursivo-identitárias. Goiânia: Cânone Editorial, 2013. p. 130-159. 
um córrego poluído que tem pertinho da escola e na hora do recreio ficavam jogando pedras por cima do muro. Uma das estudantes é minha aluna, quando iniciamos o ano, logo na apresentação conversei com ela para saber mais detalhes da sua cultura e etnia, entretanto, ela não soube me responder nada, nem mesmo o nome da sua etnia, a única coisa que ela sabia era que a mãe estava lá para trabalhar. No decorrer das aulas conversei com o pai que não é indígena, mas desde os anos anteriores é conhecido como o "pai dos indiozinhos". Ele contou um pouco da história da etnia Guajajara e relatou diversas dificuldades que as crianças enfrentam nesse modelo de sociedade. Comecei a trazer um pouco da cultura dos Guajajaras para dentro de sala os costumes e hábitos da etnia. Enfrentei muitos desafios. O maior deles foi não ter conhecimento sobre as culturas indígenas em geral e nem mesmo a respeito da etnia em específico, não saber o significado das palavras que era habitual em sua aldeia e também em relação aos alunos, pois eles não a viam como indígena, falavam que "os índios se vestiam diferente dela $\mathrm{e}$ ficavam com o pé descalço". Como minha turma é de quinto ano, podemos fazer um debate em relação às transformações sociais que ocorrem e as mudanças das vestimentas do período colonial até a atualidade. Foi bem bacana, ela se sentia mais feliz, com sorriso no rosto e começou a levar alguns objetos indígenas como cocar, instrumentos musicais. Nos conselhos de classe começamos a dialogar a respeito da importância em falar o nome da etnia e não mais os indiozinhos.

Quando o professor se empenha para conhecer da origem e da realidade de seus alunos, respeitando a cultura e a singularidade de cada ser humano, de fato, há a construção de uma educação libertadora e os frutos são colhidos dentro e fora das paredes da escola. Já no roteiro referente à aula $\mathrm{n}^{\circ} 07$, novamente percebemos uma partilha de cunho pessoal, onde a aluna relata seu desconhecimento sobre os movimentos negros e como sua educação rígida e militar influenciou para a ausência de diálogos sobre as políticas de cotas, por exemplo.

Dessa reflexão podemos notar a importância de abordar temáticas muitas vezes ignoradas na formação de professores, bem como revelou a reflexão realizada pela discente, em seu processo de autoeducação. Aluna Maria:

Fazer a leitura do texto "A educação escolar quilombola" foi muito importante para mim pois eu desconhecia os movimentos negros antes de 2000. Sou de uma família tradicional, militar, meu pai não concordava com cotas raciais e nunca tínhamos conversas a respeito de políticas defensoras de uma classe minoritária. Sempre estudei em escola pública, pude conhecer professores politizados que nos mostravam o outro lado da moeda e assim podíamos ter mais argumentos ao defender as classes minoritárias. No entanto saber que os movimentos negros começaram as suas articulações em 1871 foi um saber ampliado que adquiri hoje.

A aluna Joana, dentro da temática abordada no roteiro de $\mathrm{n}^{\circ} .07$, acerca da educação quilombola e das desigualdades sociais e educacionais ${ }^{4}$, fez um relato pessoal de sua condição enquanto criança negra, demonstrando que a sala de aula foi espaço propício

4 SOUZA, Maria Antônia de. Educação do campo, desigualdades sociais e educacionais. Educação \& Sociedade (Impresso), v. 33, p. 745-763, 2012. CAMPOS, Margarida Cássia; GALINARI, Tainara Sussai. A educação escolar quilombola e as escolas quilombolas no Brasil. Revista NERA (UNESP), v. 35, p. 199-217, 2017. 
para a partilha de suas lembranças e de como sua vivência impactou sua atuação profissional enquanto professora. Aluna Joana:

Ser preta em uma escola no interior de Goiás, e com um número de alunos consideravelmente brancos não foi uma tarefa fácil. Ouvir piadas, ter apelido como "pinche, chicletinho de onça, kichute, escrava, pé preto"... ter que se sentir culpada por não ser "igual", fazer parte de um grupo que não te vê como parte, ser excluída das atividades de apresentação pelo fato de não ser "bonitinha". São enfrentamentos que não podemos entender/aceitar, mas que ouvia das minhas professoras, (deixa para lá). Até hoje me pergunto o que seria deixar para lá? Ainda percebo como professora esses comportamentos arraigados no contexto das escolas de modo geral, um pouco disfarçado mais latente. As legislações estão emergindo o direito de ser, pertencer e permanecer. Um desafio para grupos, indivíduos, famílias, professores, alunos, gestores. Por essa educação que lutamos hoje é que acredito em um futuro próximo com pessoas mais justas, melhores, informadas, conscientes. Ouvi de uma mãe de criança autista "minha filha está na escola concluindo o $5^{\circ}$ ano do ensino fundamental e sempre me perguntam se ela sabe ler. Minha resposta é mesma, ainda não, explico que tal situação não me faz triste. Na verdade, estou muito feliz e realizada em saber que as crianças que conviveram com minha filha não terão comportamentos preconceituosos como os dos adultos atuais, serão livres de conceitos preconcebidos". Assim eu me liberto dos dias ruins, sigo na minha função de professorar, dialogando, construindo um ambiente escolar com uma prática educativa menos preconceituosa, seja em qual for esse espaço de construção.

A escola é também lugar para combater preconceitos, enfrentar as desigualdades e dar voz às minorias e àqueles que são por vezes marginalizados. É no convívio diário com a diversidade que podemos cultivar a esperança de uma sociedade mais justa e humana, através da formação integral, para além dos conteúdos.

O aluno Pablo, na temática do roteiro $\mathrm{n}^{\circ}$. 02, sobre os direitos humanos e a inclusão das pessoas com deficiência ${ }^{5}$, descreveu sua vivência na escola enquanto aluno com deficiência física e como a tentativa frustrada de inclusão dele em algumas atividades provocava a exclusão e o bullying. Aluno Pablo:

Outra vez, deixo o relato para reflexão das práticas pedagógicas considerando o outro e que deve ser "de" todos com algumas reflexões ao final do comentário. Como disse na aula passada, hoje, reflito lembranças da infância que podem ser trazidas ao texto, pois, quando no ginásio (hoje, Fundamental II), como forma de "inclusão" da época, fui colocado com o restante da turma para praticar as atividades da disciplina de Educação Física junto às demais crianças. Assim, o intuito era não me sentir excluído das atividades já estabelecidas pela instituição. O fato é que, por ser o único naquela condição, era constantemente comparado aos "normais", o menos (ou o último) escolhido para formação de grupo e o alvo da chacota vespertina. Esse processo acontecia em forma de bullying e também interiormente. Ora, por que eu? Seria menos traumático ficar de fora das atividades ou ser forçado a praticar o mesmo que os demais e ser comparado? A escola cumpriu seu papel de "inclusora"? A inclusão foi eficaz? E mais, enquanto

5 SANTOS, Boaventura Sousa. Direitos humanos: o desafio da interculturalidade. Revista Direitos Humanos, Brasília, n. 2, p. 10-18, jun. 2009. MANTOAN, Maria Teresa Eglér. Inclusão, diferença e deficiência: sentidos, deslocamentos, proposições. Inclusão Social, Brasília, v.10 n.2, p.37-46, jan./jun. 2017. 
professor, o que fazer quando me deparo com alunos nessas condições se as práticas de hoje permeiam o mesmo molde da época?

O olhar atento para quais práticas pedagógicas podem incentivar a igualdade e quais podem reforçar exclusões foi constantemente abordado nas rodas de conversa e se fez presente no relato do discente, pessoa com deficiência.

Ao tratar os conceitos de deficiência e as inclusões escolares, Mantoan (2017) propõe uma superação de modelo generalizante, com a defesa de que não existe um modelo universal de aluno, incentivando provocações para refletirmos sobre as capacidades e competências singulares de todos e a necessidade de inovarmos o processo de ensino-aprendizagem sob o olhar de respeito e liberdade, para garantia de uma real inclusão.

A aluna Roberta, também no supramencionado roteiro de $\mathrm{n}^{\circ}$. 02, descreve sua observação como professora de um colégio que vivencia a exclusão de um aluno com deficiência. Aluna Roberta:

Alunos/as na mesma sala, mas, que não conseguem acompanhar os demais uma inclusão que exclui. Fez-me refletir sobre minhas experiências e vivências em um Colégio do Ensino Médio, em que a inclusão era permitir o/a aluno/a com deficiência permanecesse na sala, muitas vezes apenas observando os/as colegas realizarem atividades.

Na mesma temática de inclusão, a aluna Divina fez uma partilha sobre sua formação e uma visita que realizou em uma escola de atendimento voltado apenas para alunos com deficiência, narrando que no início de sua carreira como professora não tinha a visão de como eram segregatórias e discriminatórias as políticas educacionais. Aluna Divina:

A leitura do texto da autora Mantoan me fez refletir sobre minha práxis enquanto educadora, minha formação no decorrer da minha profissão e entender os caminhos e dificuldades que tenho enfrentado no exercício da minha profissão. Ao deparar com a tema de inclusão, diferença e deficiência, pude rememorar minha formação enquanto estudante de magistério, um curso técnico, onde tive a oportunidade de visitar uma escola exclusiva para alunos com deficiência. Ainda não havia o processo de inclusão, os alunos com deficiência frequentavam instituições específicas. Naquela época não tinha a noção do quão segregacionista e discriminatório era este processo educacional, se assim posso chamá-lo, não tinha esta visão crítica e humana que tenho hoje, o que é algo compreensível uma vez que este assunto não foi abordado nem durante minha formação no magistério, nem no curso acadêmico que frequentei. Assim, quando já no exercício da minha função, me deparei com meu primeiro aluno com necessidade especial, portador de deficiência auditiva, estava totalmente despreparada, não sabia me comunicar com ele, não sabia como me conectar, não fazia parte do seu mundo e nem ele do meu. Foi difícil e frustrante demais, para ambos, creio eu. Desde então, na sala de aula, tenho me deparado com alunos com diversas deficiências, alunos com suas diferenças e singularidades. Não digo que seja um processo fácil ensinar para todos indiscriminadamente, nem sempre estou preparada para os desafios que encontro no caminho educacional. No entanto, percebo que estamos caminhando, mesmo que a passos lentos, mesmo sem a devida 
formação profissional, mesmo sem todos os suportes e as estruturas necessárias, mas mesmo assim caminhamos. Longa é a caminhada, reconheço. Grandes são os desafios que precisam ser superados. Almejo uma educação que não olhe somente para a deficiência, afinal, somos todos diferentes, mas que enxergue a pessoa, o ser humano sem qualquer adjetivação, padronização e preconceito.

Em um dos textos analisados dentro da temática de inclusão, nas rodas de conversa e também discutido pelos alunos nos roteiros, Vieira (2013) trabalha como os conhecimentos jurídicos e médicos se relacionam com a educação inclusiva ao longo da história e como as nomenclaturas refletiram paradigmas educacionais acerca da educação inclusiva, porém, com uma evolução a passos lentos e ainda distante da escola que, de fato, respeite as diferenças e estimule a singularidade e a desconstrução de padrões, entre eles o da "normalidade" e do "nível de inteligência".

Já a aluna Luana, faz relato de como as leituras rememoraram seu trabalho como voluntária em um ambulatório em Aparecida de Goiânia e como o atendimento de psiquiatria atende quadros associados às dificuldades escolares. Aluna Luana:

Tive a oportunidade de trabalhar como voluntária, por 2 anos, como supervisora de prática psicopedagógica em um ambulatório da infância e adolescência, pelo SUS de Aparecida de Goiânia, e viver experiências que foram rememoradas ao ler os textos dessa aula. O ambulatório é de psiquiatria e as crianças atendidas, em sua maioria, apresentam quadros que se associam às dificuldades escolares. Em muitos casos, são identificados sofrimento psíquico, privações culturais e baixa escolaridade dos familiares.

A equipe multidisciplinar composta pela atuação conjunta dos profissionais da educação e da saúde é importante para garantir a humanização do processo de aprendizagem dos alunos que enfrentam dificuldades.

Por sua vez, o aluno João, ao tratar também da temática da inclusão, partilhou sua história enquanto professor de língua inglesa e como acontece o trabalho do professor regente, muitas vezes alheio ao processo de inclusão dos alunos com deficiência. Aluno João:

Na escola em que trabalho, como professor de língua inglesa, há vários alunos que têm algum tipo de deficiência, com laudos médicos, e são assistidos por professores de apoio. Quero destacar, uma turma com 28 alunos, destes, temos 4 alunos com laudo. Um aluno com deficiência na fala, uma com esquizofrenia, uma com deficiência auditiva e um com TDAH. Geralmente, eles não são bem aceitos em atividades grupais, sempre ficando os 4 no mesmo grupo. As atividades, muitas vezes, são feitas pela professora e os alunos apenas as copiam. A professora que os acompanha é licenciada em pedagogia, mas sem nenhum outro tipo de preparação. Nós, professores regentes, majoritariamente, despreparados, apenas repetimos as normas padronizadas, aplicamos atividades reduzidas do conteúdo (que alguns chamam de flexibilizadas) e nos isentamos da responsabilidade de transformar o meio social desses alunos. Com isso, ao me deparar com o texto de Mantoan, com pesar, percebo que as instituições escolares (e mesmo empresas) buscam cumprir as exigências das leis, porém de forma ineficaz, uma 
vez que as crianças estão num sistema de inclusão que não as faz desenvolverem seu aprendizado e superarem suas deficiências.

Ante a todas as reflexões e excertos extraídos dos roteiros dos encontros da disciplina que serviram como lócus deste estudo, reiteramos a presença incessante de um dos operadores cognitivos do pensamento complexo que é o Princípio dialógico. Segundo Batalloso Navas (2010), o princípio dialógico busca integrar o diverso, incluir o diferente e unir o oposto em todos e em cada um dos processos de ensino e aprendizagem, independentemente das especificidades apresentadas pelos educandos e educadores. Para Morin (2007, p.109), o princípio dialógico "une de modo complementar termos antagônicos: consenso/conflito, liberdade/igualdade-fraternidade, comunidade nacional/ antagonismos sociais e ideológicos", e foi exatamente o que pudemos observar durante o decorrer da disciplina e dos relatos.

Observamos a união e complementariedade de diversos termos que se opõem, mas que ao mesmo tempo tornam-se indissociáveis como: branquitude/negritude, hetero/ homossexualidade, riqueza/pobreza, justiças/injustiças sociais, igualdade/desigualdade, inclusão/exclusão. Sob essa luz, compreendemos a presença intermitente desse operador cognitivo do pensamento complexo.

\section{CONSIDERAÇÕES FINAIS}

Partindo da análise, pela via da complexidade, de uma sala de aula criada em um contexto pandêmico que exigia o distanciamento social e, para tanto o uso de tecnologias para aulas remotas, aguçou-se o olhar para a pesquisa de como a atuação docente é capaz de criar espaços destinados à partilha de vivências e de saberes, em um processo complexo e multifacetado que é a construção de saberes.

Ao pensarmos em como as práticas docentes podem possibilitar a reflexão, a conscientização e a formação integral, notamos em cada roteiro analisado na presente pesquisa a experiência exitosa na disciplina de Educação e Diversidades do Programa de mestrado PPG-IELT, cursada durante o segundo semestre de 2020.

A relação afetiva criada entre os acadêmicos e professores foi capaz de proporcionar construção de saberes e articulações de conhecimentos e vivências que superaram as distâncias físicas, demonstrando que a sala de aula não é espaço físico, não se limita a paredes e muros, mas, por ser formada de humanos e para humanos, é viva, mutável e dinâmica. Sob essa ótica, percebeu-se a compreensão, mesmo que muitas vezes sem cunho teórico complexo expositivo, de diversos elementos do pensamento complexo, tais como: compreensão e aceitação da multidimensionalidade humana; a não fragmentação dos conceitos, mas a ampliação dos mesmos numa perspectiva transdisciplinar; a observação de alguns dos princípios do pensamento complexo, como a reinserção do sujeito cognoscente na produção e seu próprio conhecimento; o princípio sistêmico-organizacional; princípio hologramático; princípio dialógico.

O que se viu foi a construção de um espaço de sala de aula propício para trocas de experiência e construção de conhecimentos que transpuseram a produção científica e 
acadêmica, relembrando o compromisso do ensinar para além das dificuldades, conectando pessoas e estabelecendo diálogos de respeito e de interlocuções, tão necessários para se trabalhar a temática da diversidade, não em conceitos e legislações, mas em vivências e histórias reais, tudo isso enriquecido pelos relatos de autores, pesquisadores e convidados que durante as rodas de conversa se fizeram presentes, contribuindo para a construção do que nós, autores, denominamos sala de aula viva.

A presente pesquisa não se propõe a esgotar a temática tão ampla da sala de aula e das práticas pedagógicas, mas visa estimular reflexões complexas e transdisciplinares sobre experiências produtivas em tempos tão sombrios para a educação, tendo um olhar ampliado, religado, não fragmentador, multidimensional e também multirreferencializado, a fim de abarcar as mais diversas e específicas características da personalidade humana.

\section{REFERÊNCIAS}

ALENCAR, Francisco. Educação no Brasil: um breve olhar sobre o nosso lugar. GENTILI, Pablo. Educar na esperança em tempos de desencanto. Petrópolis: Vozes, 2001.

ALMEIDA, Ana Rita Silva. Emoção Na Sala de Aula (a). Papirus Editora, 2001.

ARANTES, Valéria Amorim. Afetividade na escola: alternativas teóricas e práticas. São Paulo: Atlas, 2003.

BATALLOSO NAVAS, Juan Miguel Batalloso. Didáctica deconstructiva y complejidad: algunos principios. In. MORAES, Maria Cândida; NAVAS, Juan Miguel Batalloso (Orgs.). Complexidade e transdisciplinaridade em Educação: teoria e prática docente. Rio de Janeiro: Wak Editora, 2010. p. 63-107.

BORTONI-RICARDO, Stella Maris. O professor pesquisador: introdução à pesquisa qualitativa. São Paulo: Parábola, 2008.

CANDAU, Vera. Maria. (org).. Reinventar a Escola. Petrópolis: Vozes, 2000.

ELIAS, Marisa Del Cioppo (org). Pedagogia Freinet, Teoria e Prática. Campinas, SP: Papirus, 1996.

FLICK, Uwe. Introdução à metodologia da pesquisa: um guia para iniciantes. Porto Alegre: Penso, 2013.

FREIRE, Paulo. Pedagogia da Autonomia. Saberes necessários à prática educativa. São Paulo: Paz e Terra, 1996. HOOKS, Bell. Ensinando a transgredir: a educação como prática de liberdade. São Paulo: Martins Fontes, 2013. MANTOAN, Maria Teresa Eglér. Inclusão, diferença e deficiência: sentidos, deslocamentos, proposições. Inclusão Social, Brasília, v.10 n.2, p.37-46, jan./jun. 2017.

MATURANA, Humberto. Emoções e Linguagem na Educação e na Política. Belo Horizonte: UFMG, 2002.

MORAES, Maria Cândida. VALENTE, José Armando. Como pesquisar em educação a partir da complexidade e da transdisciplinaridade? São Paulo: Paulus, 2008.

MORAIS, Regis de org. Sala de aula: que espaço é esse? 5. ed. Campinas, SP: Papirus, 1991.

MORIN, Edgar. Os sete saberes necessários à educação do futuro. 5. Ed. São Paulo: Cortez; Brasília, DF: UNESCO, 2007.

NICOLESCU, Basarab. O Manifesto da transdisciplinaridade. São Paulo: Triom, 1999.

PARO, Vitor Henrique. Educação como Exercício do Poder: Crítica ao senso comum em educação. 2. ed. São Paulo: Cortez, 2010.

PIMENTA, Selma Garrido; ANASTASIOU, Léa das Graças Camargos. Docência do Ensino Superior. São Paulo: Cortez, 2010.

PINO, Angel. (mimeo). A Afetividade e vida de relação. Campinas, UNICAMP: FE, 2000.

SUANNO, Marilza Vanessa Rosa Suanno. Didática e trabalho docente sob a ótica do pensamento complexo e da transdisciplinaridade. 2015. 493p. Tese de Doutorado em Educação, pelo Programa de Pós-Graduação Stricto Sensu em Educação, pela Universidade Católica de Brasília-UCB, Brasília-DF, 2015. 
TASSONI, Elvira Cristina Martins et al. Afetividade e produção escrita: a mediação do professor em sala de aula. 2000.

TEIXEIRA, Inês. Os professores como sujeitos socioculturais. In: DAYRELL, Juarez (org.). Múltiplos olhares sobre a educação e cultura. Belo Horizonte: Editora UFMG, 1996. p. 179- 194.

VALDEZ, Diane. As relações interpessoais e a Teoria da Mente no contexto educativo. Pátio Revista Pedagógica, Porto Alegre, Artmed, ano VI, v.23, set/out 2002.

VASCONCELOS, Mário Sérgio, A afetividade na escola: alternativas teóricas e práticas. Educ. Soc., Campinas, vol.25, maio/agosto, 2004.

VIEIRA, Ubiratan. Descontinuidades a inclusão e da exclusão na educação de pessoas com deficiência no Brasil. In: PINTO, Joana Plaza; BRANCA, Falabella Fabrício (Orgs.). Exclusão Social e Microrresistências. Goiânia: Cânone Editorial, 2013. 